\title{
Incorporation of selenium-75 into semen and reproductive tissues of bulls and rams
}

\author{
F. R. Pond*§, M. J. Tripp*ף, A. S. H. Wu†, P. D. Whanger* and \\ J. A. Schmitz \\ Departments of * Agricultural Chemistry, and $\uparrow$ Animal Science, and $\ddagger$ School of Veterinary Medicine, \\ Oregon State University, Corvallis, Oregon 97331, U.S.A.
}

\begin{abstract}
Summary. After intramuscular injections of $500 \mu \mathrm{Ci}{ }^{75} \mathrm{Se}$, semen was collected periodically over a 63-day period from a selenium-deficient and a selenium-injected ram which were then killed for collection of the reproductive organs for the gel filtration studies. Testes, accessory glands and semen were also obtained from a bull injected intravenously with ${ }^{75} \mathrm{Se}$. Gel filtration (Sephadex G 150) of ram testis cytosol resulted in $4{ }^{75} \mathrm{Se}$ peaks (Ve/Vo ratios of $1 \cdot 1,1 \cdot 5,2 \cdot 3,2 \cdot 9$ ). In the selenium-injected ram the glutathione peroxidase (GSH-Px) peak (Ve/Vo 1.5) predominated, but in the selenium-deficient ram, radioactivity of the GSH-Px peak was less than that of the higher molecular weight peak (Ve/Vo 1-1). Gel filtration chromatograms of bull testis cytosol yielded $5{ }^{75} \mathrm{Se}$ peaks (Ve/Vo $1 \cdot 1,1 \cdot 5,1 \cdot 9,2 \cdot 4,2 \cdot 8$ ).

In chromatograms of ram seminal plasma on Sephacryl S-200 there were 2 major (Ve/Vo 1.4, 1.1) and 2 minor peaks (Ve/Vo 1.7, 2.4). ${ }^{75} \mathrm{Se}$ increased with time up to 49 days after injection in all peaks. ${ }^{75} \mathrm{Se}$-labelled bull seminal plasma yielded $2{ }^{75} \mathrm{Se}$ peaks $\left(\mathrm{Ve} / \mathrm{Vo}_{1} \cdot 1,1 \cdot 4\right)$ which corresponded to the major peaks of ram seminal plasma. Bull and ram seminal plasma GSH-Px activities per mg protein were comparable ( 28 and 29 nmol $\mathrm{NADPH}_{\mathrm{ox}} / \mathrm{min}$, respectively), but when expressed per $\mathrm{ml}$ seminal plasma, activity of the bull was more than 7 times the highest activity of ram seminal plasma (2908 and $385 \mathrm{nmol}^{\mathrm{NADPH}} \mathrm{ox}_{\mathrm{omin}} / \mathrm{m}$, respectively). Seminal vesicles of the bull and rams, and the bull prostate gland possessed high GSH-Px activity, but bull and ram Cowper's glands had low GSH-Px activity.
\end{abstract}

\section{Introduction}

Selenium-75 has been shown to be incorporated into developing spermatozoa of rats (Burk, Brown, Sealy \& Scaief, 1972), mice (Gunn, Gould \& Anderson, 1967), and bulls (Smith, Senger, McCutchan $\&$ Landa, 1979). Data for bulls were thought to indicate selenium incorporation by spermatids (Smith et al., 1979). However, Gunn \& Gould (1970) interpreted the results from rat experiments as evidence of selenium incorporation in spermatogenesis earlier than the spermatid stage. Presumably, this incorporation of selenium into reproductive organs is critical since selenium deficiency has been shown to result in impaired reproductive performances in several species of animals including rats (Wu, Oldfield, Whanger \& Weswig, 1973) and sheep (Hartley, 1963).

$\S$ Present address: Department of Biology, Yankton College, Yankton, South Dakota 57078, U.S.A

II Present address : Boehringer Mannheim Diagnostics, Department of Chemistry Development, 7800 West Park Drive, P.O. Box 36329, Houston, Texas 77036, U.S.A. 
Selenium-dependent glutathione peroxidase (GSH-Px; EC 1.11.1.9) activity has been found in semen of ram, dog, goat and man, but has not been detected in boar or rabbit semen (Li, 1975). GSH-Px activity has been detected in bull seminal plasma but not the spermatozoa (Brown, Senger, Stone, Froseth \& Becker, 1977; Smith et al., 1979).

Gel filtration showed selenium to be associated with at least 4 proteins in rat testis cytosol, two of which possessed peroxidase activity (Prohaska, Mowafy \& Ganther, 1977). One of these appeared to be selenium-dependent and the other one non-selenium-dependent. McConnell, Burton, Kute \& Higgins (1979) demonstrated selenium binding to 3 cytosol proteins in rat testis with Ultragel ACA-22 chromatography. However, to date, no work has been reported with testis cytosols of other species of animals or with cytosols from other reproductive organs from any animal. GSH-Px is the only known selenium-dependent mammalian enzyme (Rotruck et al., 1973). However, evidence has been presented for selenium-containing proteins other than GSH-Px in other tissues (Black, Tripp, Whanger \& Weswig, 1978; Burk \& Gregory, 1982) in animals. Hence, the present work was undertaken to obtain descriptive information for the presence of selenium-containing proteins other than GSH-Px in reproductive organs of the ram and bull as well as to provide data on selenium metabolism in the reproductive tissues of these animals.

\section{Materials and Methods}

Two 9-month-old, predominantly Suffolk rams, one selenium-deficient ( < 0.01 p.p.m. whole blood $\mathrm{Se}$ ) and one injected with selenium ( $0 \cdot 14$ p.p.m. whole blood Se), weighing approximately $53 \mathrm{~kg}$ and $68 \mathrm{~kg}$ respectively, were injected intramuscularly in the neck with $500 \mu \mathrm{Ci}$ carrier-free ${ }^{75} \mathrm{Se}$ as sodium selenite (obtained from New England Nuclear Corp., Boston, MA). Both rams had been grazing low-selenium grass pasture and one was injected 3 times with $5 \mathrm{mg}$ selenium as sodium selenite at 2-week intervals before the start of the experiment. Both rams were fed low-selenium alfalfa hay (0.012 p.p.m. Se) during the experiment. The reason for using a Se-deficient (Ram D) and Se-treated (Ram S) ram was to determine the influence of selenium status on ${ }^{75}$ Se incorporation into the reproductive organs. Second and third injections of $500 \mu \mathrm{Ci}$ were given 10 and 3 days before necropsy, which was 73 days after the initial injection. The last injections were given to ensure adequate labelling in the tissues to be analysed. Semen was collected by electroejaculation periodically during the 63-day interval between first and second injections. Spermatozoa were separated from seminal plasma by centrifugation at $1500 \mathrm{~g}$ for $15 \mathrm{~min}$ and washed once with $0.9 \%$ $(w / v) ~ N a C l$. Sperm counts were made for all ejaculates. The animals were killed by intravenous injection of pentobarbitone sodium, followed by exsanguination. Selected tissues were removed at necropsy, portions dissected for counting and the remainder immediately frozen on solid $\mathrm{CO}_{2}$ and stored at $-70^{\circ} \mathrm{C}$ for later assay. ${ }^{75} \mathrm{Se}$-labelled bull semen and reproductive tissues were obtained from a bull injected with sodium ${ }^{75}$ selenite (Smith et al., 1979) through the courtesy of Dr P. L. Senger (Department of Animal Science, Washington State University, Pullman, WA). Samples arrived at our laboratory packed in solid $\mathrm{CO}_{2}$ and were stored at $-70^{\circ} \mathrm{C}$ until assayed. Bovine and ovine tissue cytosols were prepared by homogenization in 5 volumes of $10 \%$ sucrose, $0.1 \mathrm{M}$-phosphate buffer, $\mathrm{pH} 6 \cdot 3$, with a Potter-Elvehjem homogenizer followed by centrifugation at $161000 \mathrm{~g}$ for $90 \mathrm{~min}$ at $4^{\circ} \mathrm{C}$.

Seminal plasma was chromatographed on Sephadex G-150 $(2 \times 115 \mathrm{~cm})$ or Sephacryl S-200 $(2 \times 100 \mathrm{~cm})$ columns. All samples of tissue cytosols were applied to Sephadex G-150 columns $(2 \times$ $115 \mathrm{~cm}$ ). All columns were equilibrated with $0 \cdot 1 \mathrm{M}$-phosphate buffer ( $\mathrm{pH} \mathrm{6.3)} \mathrm{containing} 0.03 \%$ EDTA and $0.01 \% \mathrm{NaN}_{3}$, and run at $4{ }^{\circ} \mathrm{C}$. A flow rate of about $21 \mathrm{ml} / \mathrm{h}$ was maintained with a peristaltic pump. The columns were standardized with blue dextran, bovine serum albumin, $\gamma$ globulin, ovalbumin, soybean trypsin inhibitor, and riboflavin. Effiuent fractions were monitored at 254 or $280 \mathrm{~nm}$. Seminal plasma and selected column fractions were assayed for protein content by the method of Lowry, Rosebrough, Farr \& Randall (1951), using bovine serum albumin as standard. 
Radioactivity was measured with a Beckman 8000 Gamma Counter. GSH-Px activity was determined by the coupled-enzyme procedure of Paglia \& Valentine (1967) as modified by Whanger, Weswig, Schmitz \& Oldfield, (1977). When applicable, the data were subjected to statistical analysis to calculate the $t$ test or regression coefficients (Steel \& Torrie, 1980).

\section{Results}

When the sperm counts were made, the motility and morphology were evaluated. There were no differences between Rams $D$ and $S$ with respect to sperm quality.

Four ${ }^{75} \mathrm{Se}-1$ abelled peaks (Ve/Vo ratios $\left.1 \cdot 1,1 \cdot 5,2 \cdot 3,2 \cdot 9\right)$ were obtained from gel filtration of ram testis cytosol (Text-figs la \& 1b). In Ram S (Text-fig. lb) the GSH-Px peak (Ve/Vo 1.5) predominated, but in Ram D (Text-fig. 1a), radioactivity in the GSH-Px peak was lower than that of the higher molecular weight peak $(\mathrm{Ve} / \mathrm{Vo} 1 \cdot 1)$. Gel filtration of bull testis cytosol resulted in 5 peaks (Ve/Vo ratios of $1 \cdot 1,1 \cdot 5,1 \cdot 9,2 \cdot 4,2 \cdot 8)$ and GSH-Px activity was detected in the elution peaks having $\mathrm{Ve} /$ Vo ratios of 1.5 (Text-fig. 1c).

Enzyme activity was measured in cytosols from tissue homogenates. GSH-Px activity (nmol $\mathrm{NADPH}_{\mathrm{ox}} / \mathrm{min} \cdot \mathrm{mg}$ protein ${ }^{-1}$ ) was 99 in ram and 108 in bull testis cytosol, 89 and 61 in ram and bull seminal vesicle cytosols, respectively, and 38 and 22 in ram and bull Cowper's gland cytosols, respectively. Bull prostate gland cytosol activity was 64 . Calculation of correlation coefficients indicated that levels of ${ }^{75} \mathrm{Se}$ in tissues correlated $(r=0.88)$ with the GSH-Px activities $(P<0.001)$.

In the chromatographic elution profiles for ram and bull seminal plasma, 2 predominant peaks (Ve/Vo ratios $1 \cdot 1,1.4$ ) and possibly 2 minor peaks (Ve/Vo ratios 1.7 and 2.4 ) were found (Text-figs ld, le \& 1f). The gel filtration pattern for seminal fluid from Ram D (Text-fig. 1d) was similar to that for Ram S (Text-fig. 1e), but GSH-Px activity was not detected in samples from either animal. The ${ }^{75} \mathrm{Se}$ radioactivity of bull seminal plasma also eluted mostly in 2 peaks during gel filtration (Ve/Vo ratios of $1 \cdot 1,1 \cdot 4$; Text-fig. 1f), but GSH-Px activity was detected in eluted fractions of bull seminal plasma ( $\mathrm{Ve} /$ Vo ratio $1 \cdot 4)$.

In the seminal vesicle and Cowper's gland cytosols from the rams and the bull there were 2 or 3 broad ${ }^{75}$ Se peaks (Text-fig. 2). The GSH-Px activity was associated with the major peak of seminal vesicles from both rams (Text-fig. $2 \mathrm{a}$ ) and the bull (Text-fig. 2c), but no activity was detected in the cytosol of the Cowper's glands from the bull or rams (Text-figs $2 b$ \& 2d). At least $3^{75}$ Se peaks were apparent in Cowper's gland cytosol of the bull (Ve/Vo ratios of $1 \cdot 2,1 \cdot 5,2 \cdot 0$ ).

Prostate gland cytosol from the bull (Text-fig. 2e) possessed $3{ }^{75} \mathrm{Se}$ gel filtration peaks (Ve/Vo ratios of $1 \cdot 1,1 \cdot 5,2 \cdot 1)$. Essentially all of the GSH-Px activity was seen in the predominant ${ }^{75}$ Se peak $(\mathrm{Ve} / \mathrm{Vo} 1 \cdot 5)$ but a small amount of activity was also present in the first peak (Ve/Vo ratio of 1·1).

In the seminal plasma of Ram D, the percentage contribution of each peak to total seminal plasma radioactivity varied with time after injection. When normalized to semen volume, the c.p.m. of ${ }^{75} \mathrm{Se}$ for each peak reached a maximum near the 49 th day after injection (Text-fig. 3a). All of the peaks showed similar patterns with time.

GSH-Px activity per $\mathrm{mg}$ protein varied greatly in both rams during the experimental period (Text-fig. 3b). Activity in seminal plasma of Ram S was similar with hydrogen peroxide or $t$-butyl peroxide as substrate. Until Day 40 , this activity was significantly higher $(P<0.05)$ than that from Ram D. GSH-Px activity ( $\mathrm{nmol} \mathrm{NADPH}_{\mathrm{ox}} / \mathrm{min}$ ) per $\mathrm{ml}$ seminal plasma had a maximum value in Ram S of 385, and of 2908 for bull seminal plasma (data not shown). However, when activity was expressed on a per mg protein basis, the values of these samples were essentially identical at 29 for the ram and 28 for the bull.

Two concentration peaks of isotope were found in ejaculated spermatozoa over a 63-day period in Ram $D$ at 32 and 52 days (Text-fig. 3c) and $\operatorname{Ram} S$ at 39 and 52 days (Text-fig. 3d). By Day 21, the spermatozoa of Ram D contained $94 \%$ of the ${ }^{75} \mathrm{Se}$ counts in whole semen and this level was maintained throughout the remainder of the experimental period. In Ram $S$ the percentage of counts in the spermatozoa increased more slowly, reaching a plateau after about 35 days. 


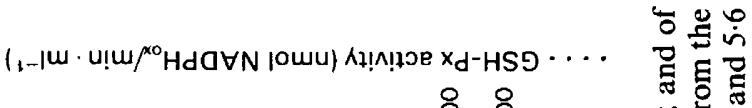

\& \& 8 i 仓
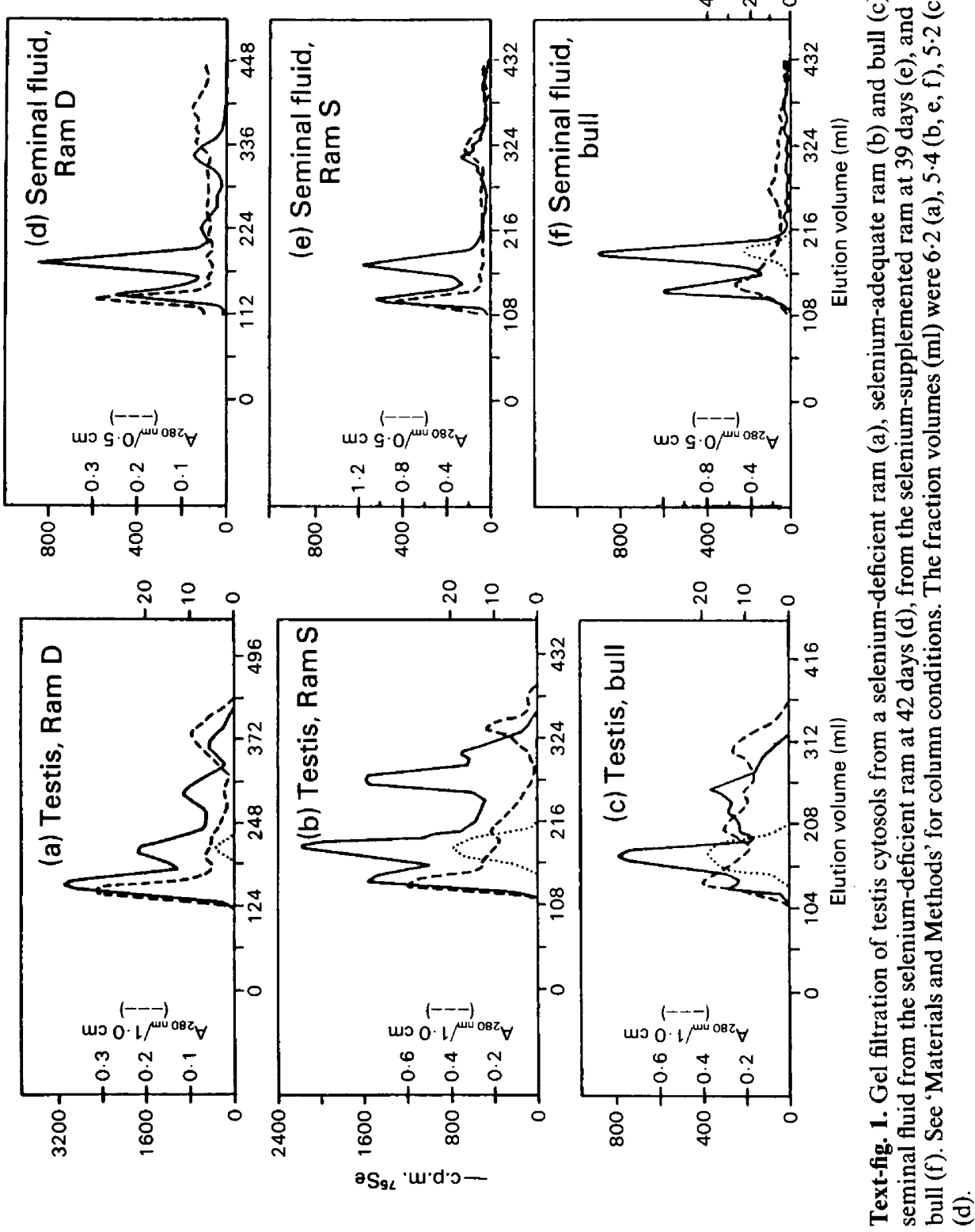


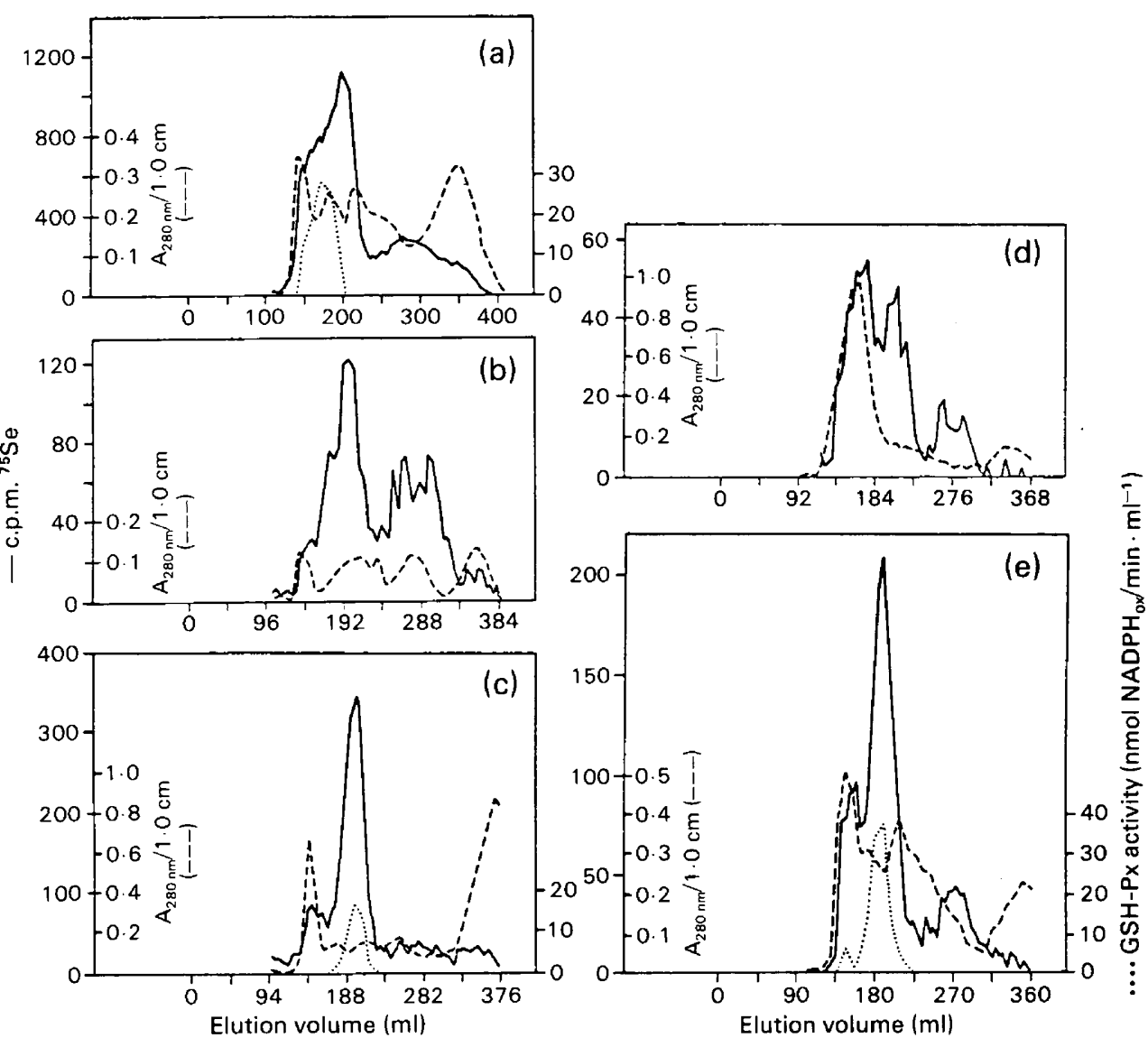

Text-fig. 2. Gel filtration of cytosols from selenium-supplemented ram seminal vesicle (a), and Cowper's gland (b); and from bull seminal vesicle (c), Cowper's gland (d), and prostate gland (e). See 'Materials and Methods' for column conditions. The fraction volumes (ml) were 4.8 (a, b) 4.7 (c), $4.6(\mathrm{~d})$ and $5 \cdot 4(\mathrm{e})$.

\section{Discussion}

There was a correspondence between $\mathrm{Ve} / \mathrm{Vo}$ ratios of the ${ }^{75} \mathrm{Se}-\mathrm{labelled}$ gel filtration peaks from ram testis cytosol and 4 of the 5 bull testis cytosol peaks. The additional peak in bull testis cytosol had a $\mathrm{Ve} / \mathrm{Vo}$ ratio of 1.9 . These results indicate that there are other selenium-containing proteins in bovine and ovine male reproductive tract in addition to GSH-Px. This is consistent with work indicating other selenium-containing proteins besides GSH-Px in ovine heart and muscle (Black $e t$ al., 1978). In the present study some of the non-GSH-Px selenium-containing peaks were nearly or as high as the GSH-Px peak. Also, the selenium status of the animal influences the incorporation of ${ }^{75} \mathrm{Se}$ into various cytosolic proteins since more radioactivity was present in GSH-Px in testis of Ram S than Ram D (Text-figs 1a \& 1b). In both rams and the bull, the protein eluting with the void volume was consistently a large component of the seminal fluid (Text-figs $2 \mathrm{a} \& 2 \mathrm{c}$ ). Evidence for other selenium-containing proteins besides GSH-Px has also been presented for rat testis (Prohaska et al., 1977; McConnell et al., 1979) and rat liver and plasma (Burk \& Gregory, 1982). This suggests that non-GSH-Px selenium could play a major role in metabolism of the reproductive organs. 


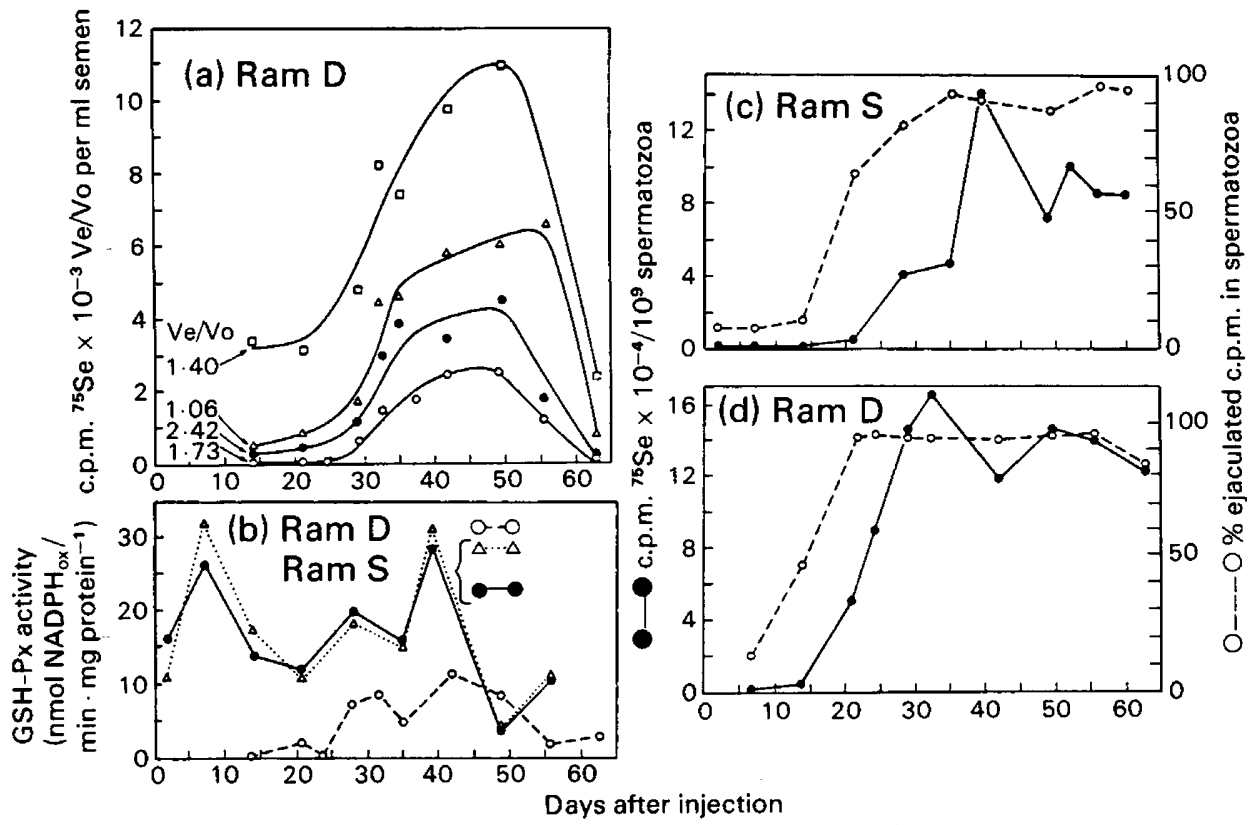

Text-fig. 3. Gel filtration of seminal plasma from the selenium-deficient ram (a); glutathione peroxidase activity in seminal plasma of the selenium-deficient $\left(\mathrm{O}---\mathrm{O}, \mathrm{H}_{2} \mathrm{O}_{2}\right.$ as substrate) and selenium-injected $\left(\triangle \cdots \triangle, t\right.$-butyl $\mathrm{O}_{2}$ as substrate and $-\longrightarrow, \mathrm{H}_{2} \mathrm{O}_{2}$ as substrate) ram (b); and radioactive selenium in ejaculated spermatozoa and \% of total ejaculated counts in spermatozoa for the selenium-supplemented (c) and selenium-deficient (d) rams.

Cummins \& Martin (1967) assessed the strength of selenium binding to protein by alkaline dialysis. Bound selenite can be displaced from its binding site by increasing the $\mathrm{pH}$ of its environment. McConnell et al. (1979) found that $87 \%$ of the radioactivity is lost from ${ }^{75} \mathrm{Se}-$ labelled rat testis cytosol after overnight dialysis against $0.5 \mathrm{M}-\mathrm{NaOH}$ whereas under denaturing or reducing conditions at a neutral $\mathrm{pH}$ relatively little label was lost. In the present work dialysis of bull and ram testis cytosol for $24 \mathrm{~h}$ against various reagents $(0 \cdot 1 \mathrm{M}$-phosphate buffer, $\mathrm{pH} 6 \cdot 3,0 \cdot 1 \mathrm{M}$ Tris, $\mathrm{pH} 11 \cdot 0$, and $0 \cdot 1 \mathrm{M}$-mercaptoethanol) suggests greater binding stability of selenium to the GSH-Px peak than to the other proteins (data not shown).

Selenium is well known to be a component of the Se-dependent GSH-Px (Rotruck et al., 1973). Although no appreciable activity of GSH-Px has been found in spermatozoa, selenium incorporation into proteins of reproductive tissue cytosols and seminal plasma suggests that selenium may protect spermatozoa, via seminal GSH-Px, from the damaging effects of peroxide radicals. The findings of the present study also substantiate the belief that selenium may have a role in reproduction as a structural component of sperm cells (Calvin, 1978; Calvin \& Cooper, 1979) or as a component of proteins other than GSH-Px (Bull \& Oldfield, 1967; Black et al., 1978; Burk \& Gregory, 1982).

Although the peak of incorporation is slightly shorter for bulls, the pattern for incorporation of selenium into semen between bulls and rams is very similar. Whole semen ${ }^{75} \mathrm{Se}$ counts in the bull (Smith et al., 1979) reached a maximum about 38 days after injection and declined thereafter. As indicated in the present study, the percentage of ejaculated counts in spermatozoa reached a plateau at 20 days in Ram D and at 35 days in Ram S (Text-figs 3c \& 3d). It took 49 days for the selenium to reach maximum seminal values (Text-fig. 3a). This pattern of incorporation parallels the formation of new spermatozoa. In rams the seminal plasma count tended to parallel the counts 
in the spermatozoa, but at peak ${ }^{75} \mathrm{Se}$ levels the sperm counts were nearly 10 -fold those of the seminal plasma.

Presumably, peroxidase activity in seminal plasma is important in reducing oxidative damage to the spermatozoa, and its consequent immobilization (Tabor \& Rosenthal, 1956; Mann, 1964). Hydrogen peroxide is produced in seminal plasma and testes of various species by spermine oxidase activity (Mann, 1964). Also, Tabor \& Rosenthal (1956) found that reduced glutathione, but not catalase, prevented immobilization of spermatozoa by spermine oxidase. This suggests a role of GSH-Px in seminal plasma. The similar activity of GSH-Px upon hydrogen peroxide or $t$-butyl hydroperoxide in seminal plasma of Ram S (Text-fig. 3b) suggests that all of the GSH-Px is the selenium-dependent enzyme (Lawrence \& Burk, 1976). These two substrates are used to distinguish between the selenium dependent and non selenium dependent GSH-Pxs.

Semen from a number of animals is known to possess GSH-Px activity (Li, 1975; Brown et al., 1977). Data in the present study suggest that the prostate gland may contribute a large amount of the GSH-Px in bull seminal plasma. In the rams and bull, the Cowper's glands did not accumulate ${ }^{75} \mathrm{Se}$ to the degree that seminal vesicle or prostate glands did and presumably do not contribute significantly to seminal GSH-Px. While seminal vesicles show high GSH-Px activity, they are also known to possess high prostaglandin synthesis activity, which has been reported to involve GSHPx (Lands, Lee, \& Smith, 1971; Nugteren \& Hazelhof, 1973). Therefore, GSH-Px could function in these glands in prostaglandin synthesis.

Normally, prostaglandin (PG) E levels exceed those of PGF in seminal plasma. GSH-Px accelerates production of PGE but decreases that of PGF (Lands et al., 1971; Nugteren \& Hazelhof, 1973). It would therefore be expected that PGE levels will reflect the selenium status of the animal. In support of this, Vincent (1974) postulated a relationship between PG level and selenium status of animals, and Karim (1972) has shown that PGE in human semen may assist sperm transport while PGF is antagonistic to this action.

The selenium that accumulates in ram and bull testes is incorporated into developing spermatozoa. Smith et al. (1979) presented evidence that selenium is incorporated by spermatids of the bull. In the present study, the high percentage of ${ }^{75} \mathrm{Se}$ counts in the spermatozoa collected from Ram D between Days 21 and $56(\sim 94 \%$ of whole semen counts) suggests an incorporation during or before the spermatid stage. Consistent with this, Gunn \& Gould (1970) argued that selenium incorporation in rat spermatozoa probably occurs during the secondary spermatocyte or early spermatid stage. Selenium does not, however, appear to be incorporated by mature spermatozoa of the ram (present study), bull (Smith et al., 1979) or rat (Gunn \& Gould, 1970).

We thank Dr P. L. Senger (present address Department of Animal Science, Pennsylvania State University, University Park, PA 16802, U.S.A.) for the bull samples. This work is part of a thesis submitted by F.R.P. to the Graduate School of Oregon State University in partial fulfillment of the Ph.D. degree, and was supported in part by N.I.H. grant NS 07413 from the National Institutes of Neurological and Communicative Disorders and Stroke.

Oregon Agricultural Experiment Station Technical Paper No. 5778.

\section{References}

Black, R.S., Tripp, M.J., Whanger, P.D. \& Weswig, P.H. (1978) Selenium proteins in ovine tissues. III. Distribution of selenium and glutathione peroxidases in tissue cytosols. Bioinorg. Chem. 8, 161-172.

Brown, D.V., Senger, P.L., Stone, S.L., Froseth, J.A. \& Becker, W.C. (1977) Glutathione peroxidase in bovine semen. J. Reprod. Fert. 50, 117-118.

Bull, R.C. \& Oldfield, J.E. (1967) Selenium involvement in the oxidation by rat liver tissue of certain tri- carboxylic acid cycle intermediates. J. Nutr. 91, 237246.

Burk, R.F. \& Gregory, P.E. (1982) Some characteristics of ${ }^{75} \mathrm{Se}-\mathrm{P}$, a selenoprotein found in rat liver and plasma, and comparison of it with selenoglutathione peroxidase. Archs Biochem. Biophys. 213, 73-80.

Burk, R.F., Brown, D.G., Sealy, R.J. \& Scaief, C.C., III (1972) Influence of dietary and injected selenium in whole-body retention, route of excretion and tissue 
retention of $75-\mathrm{SeO}_{3}{ }^{2-}$ in the rat. J. Nutr. 102, 10491056.

Calvin, H.I. (1978) Selective incorporation of selenium75 into a polypeptide of the rat sperm tail. $J$. exp. Zool. 204, 445-452.

Calvin, H.I. \& Cooper, G.W. (1979) A specific selenopoly peptide associated with the outer membrane of rat sperm mitochondria. In The Spermatozoon, pp. 135-140. Eds D. W. Fawcett \& J. M. Bedford. Urban and Schwarzenberg, Inc., Baltimore.

Cummins, L.M. \& Martin, J.L. (1967) Are selenocystine and selenomethionine synthesized in vivo from sodium selenite in mammals? Biochemistry, N.Y. 6, 3162-3168.

Gunn, S.A. \& Gould, T.C. (1970) Cadmium and other mineral elements. In The Testis, Vol. 3, pp. 378434. Eds A. D. Johnson, W. R. Gomes \& N. L. VanDemark. Academic Press, New York.

Gunn, S.A., Gould, T.C. \& Anderson, W.A.D. (1967) Incorporation of selenium into spermatogenic pathways in mice. Proc. Soc. exp. Biol. Med. 124, 12601263.

Hartley, W.J. (1963) Selenium and ewe fertility. Proc. N. Z. Soc. Amin. Prod. 23, 20-27.

Karim, S.M.M. (1972) Prostaglandins and human reproduction: physiological roles and chemical uses of prostaglandins in relation to human reproduction. In The Prostaglandins, pp. 71-74. Ed. S. M. M. Karim. Wiley-Interscience, New York.

Lands, W., Lee, R. \& Smith, W. (1971) Factors regulating the biosynthesis of various prostaglandins. Annls N.Y. Acad. Sci. 180, 107-122.

Lawrence, R.A. \& Burk, R.F. (1976) Glutathione peroxidase activity in selenium-deficient rat liver. Biochem. Biophys. Res. Commun. 71, 952-958.

Li, T.-K. (1975) The glutathione and thiol content of mammalian spermatozoa and seminal plasma. Biol. Reprod. 12, 641-646.

Lowry, O.H., Rosebrough, N.J., Farr, A.L. \& Randall, R.J. (1951) Protein measurement with the Folin phenol reagent. J. biol. Chem. 193, 265-275.

Mann, T. (1964) The Biochemistry of Semen and of the Male Reproductive Tract. Methuen, London.
McConnell, K.P., Burton, R.M., Kute, T. \& Higgins, P.J. (1979) Selenoproteins from rat testis cytosol. Biochim. Biophys. Acta 588, 113-119.

Nugteren, D.H. \& Hazelhof, E. (1973) Isolation and properties of intermediates in prostaglandin biosynthesis. Biochim. Biophys. Acta 326, 448-461.

Paglia, D.E. \& Valentine, W.N. (1967) Studies on the quantitative and qualitative characterization of erythrocyte glutathione peroxidase. J. Lab. Clin. Med. 70, 158-169.

Prohaska, J.R., Mowafy, M. \& Ganther, H.E. (1977) Interactions between cadmium, selenium and glutathione peroxidase in rat testis. Chem. Biol. Interact. 18, 253-265.

Rotruck, J.T., Pope, A.L., Ganther, H.E., Swanson, A.B., Hafeman, D.G. \& Hoekstra, W.G. (1973) Selenium: biochemical role as a component of glutathione peroxidase. Science, N.Y. 171, 588-590.

Smith, D.G., Senger, P.L., McCutchan, J.F. \& Landa, C.F. (1979) Selenium and glutathione peroxidase distribution in bovine semen and selenium- 75 retention by the tissues of the reproductive tract in bull. Biol. Reprod. 20, 377-383.

Steel, R.G.D. \& Torrie, J.H. (1980) Principles and Procedures of Statistics: A Biometrical Approach, 2nd edn. McGraw-Hill, New York.

Tabor, C.W. \& Rosenthal, S.M. (1956) Pharmacology of spermine and spermadine; some effects on animals and bacteria. J. Pharmac. exp. Therap. 116, 139-155.

Vincent, J.E. (1974) Prostaglandin synthesis and selenium deficiency: a hypothesis. Prostaglandins 8, 339340.

Whanger, P.D., Weswig, P.H., Schmitz, J.A. \& Oldfield, J.E. (1977) Effects of selenium and vitamin $E$ on blood selenium levels, tissue glutathione peroxidase activities and white muscle disease in sheep fed purified or hay diets. J. Nutr. 107, 1298-1306.

Wu, S.H., Oldfield, J.E., Whanger, P.D. \& Weswig, P.H. (1973) Effect of selenium, vitamin E and antioxidants on testicular function in rats. Biol. Reprod. 8, 625629.

Received 21 December 1982 